$\mathrm{ANL} / \mathrm{CP}--74100$

DE92 010253

\title{
STRUCTURAL MATERIALS FOR HIGH-HEAT FLUX APPLICATIONS
}

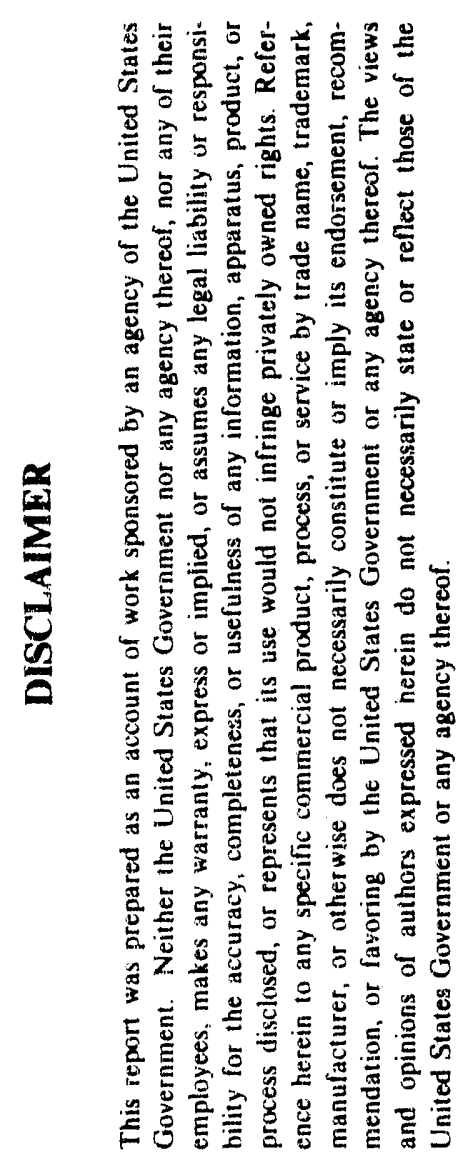

by

\author{
V.V. Rybin \\ CRISM "Prometey" \\ Leningrad USSR
}

and

Dale L. Smith

Argonne National Laboratory

Fusion Power Program

9700 South Cass Avenue

Argonne, Illinois 60439 USA

The submitted manuscript has betn authored
by a contractor of the U. S. Government
under contract No. W-31-109-ENG-38.
Accordingly, the U. S. Government retains a
nonexelusive, pyalty-free license to publigh
or reproduce the published torm of this
contribution, or allow others to th so, for
$U . S$ Government purposes.

* Work supported by the Office of Fusion Energy, U.S. Department of Energy under Contract Number W-31-109-Eng-38.

Submitted to the Fifth International Conference on Fusion Reactor Materials, Clearwater, Florida, November 17-22, 1991. 


\title{
STRUCTURAL MATERIALS FOR HIGH-HEAT FLUX APPLICATIONS
}

\author{
V.V. Rybin* and D.L. Smith** \\ *CRISM "Prometey", Leningrad USSR \\ **Argonne National Laboratory, 9700 S. Cass Ave. \\ Argonne, IL 60439 USA
}

\section{Abstract}

The structural materials for the ITER, (International Thermonuclear Experimental Reactor) divertor must perform reliably under complex and diverse operating requirements. Only a limited number of materials offer a potential for meeting these requirements for the wide temperature range of interest.

The candidate materials considered in the ITER design activity include copper, molybdenum, and niobium alloys. Molybdenum alloys being considered include dilute alloys of the TZM type and the Mo-Re system. Niobium alloys under consideration include $\mathrm{Nb}-\mathrm{V}-\mathrm{Zr}$ and $\mathrm{Nb}-2 \mathrm{r}$ systems. Copper alloys being considered include precipitation strengthened alloys of the Glidcop and MACT type, alloys of Cu-Mo system and dispersion hardened bronzes. The projected operating conditions for the ITER divertor and the criteria for evaluating the candidate materials are reviewed. This paper summarizes the data base and presents recent experimental results on these candidate divertor structural alloys. 


\section{Introduction}

Structural materials for the divertor of a fusion reactor such as the International Experimental Power Reactor (ITER) must withstand severe and diverse operating conditions $[1,2]$. The divertor must accommodate high heat loads, be compatible with the coolant and the hydrogen plasma, be readily fabricable, and have adequate resistance to radiation damage. In addition, these materials must maintain mechanical integrity under a variety of loading conditions, be reliably bonded to the candidate plasma facing materials, and be resistant to various radiation damage mechanisms such as radiation embrittlement and swelling. Desirable properties that must be considered in the selection to the candidate divertor structure for ITER include:

- High thermal conductivity

- Low thermal exparsion coefficient

- High yield strength

- High ductility/fracture toughness

- Resistance to hydrogen embrittlement

- Corrosion resistance in high velocity water

Only a limited number of materials offer a potential for meeting these requirements. The candidate materials considered in the ITER design activity include molybdenum-, niobium-, and copper alloys [2]. Copper alloys being considered include precipitation strengthened alioys of the Glidcop and MAGT type, alloys of Cu-Mo system, and dispersion hardened bronzes. Molybdenum alloys being considered include dilute T2M type and alloys of the Mo-Re system. Niobium alloys under consideration include $\mathrm{Nb}-\mathrm{V}-\mathrm{Zr}$ and $\mathrm{Nb}-2 \mathrm{r}$ systems. The criteria for selection of prime candidate divertor structural 
materials, identification of critical issues for each alloy system, and an assessment of the relevant data base for the candidate alloys are discussed in the following sections.

\section{Principles and criteria for selection of divertor structure}

This assossment of candidate divertor structural materials is based on the operating requirements specified in the ITER conceptual design [2]. The divertor structure must accommodate peak surface heat fluxes of $10 \mathrm{MW} / \mathrm{m} 2$ or higher. For the ITER design low temperature $\left(50-80^{\circ} \mathrm{C}\right)$, low pressure $(\sim 1-$ $3 \mathrm{MPa}$ ) water at $\sim 10 \mathrm{~m} / \mathrm{s}$ is proposed as the coolant. The main initial criterion is to accommodate these high heat fluxes with acceptable temperatures and stresses. Consequently, a high thermal conductivity and/or a low thermal expansion coefficient are necessary to minimize thermal stresses. A high yield stress and a low elastic modulus are also highly beneficial. The thermal stress factor, which incorporates these parameters, provides a preliminary basis for the comparison of candidate materials.

$$
M=2(1-v)(\lambda / \alpha)\left(\sigma_{y} / E\right)
$$

where $\nu, \lambda, a, \sigma_{y}$ and $\Xi$ are Poisson's ratio, thermal conductivity, thermal expansion coefficient, yield stress, and elastic modulus, respectively. A higher value of $M$ should provide a higher head load capability. For the case of ITER, which will operate in a cyclic mode, fatigue is also an important factor. In addition to the heat ioad capability, other factors that must be evaluated include:

- Eabrication/joining characteristics 
- Effects of radiation on properties, particularly embrittlement

- Thermal expansion match with plasma facing materials

- Hydrogen interactions; embrittlement and tritium inventory

- Aqueous corrosion at high velocity

- Electromagnetic interactions

- Safety related issues; activation/afterheat

The main advantages and critical issues for each of the alloy systems are evaiuated from available data.

\section{Evaluation of candidate alloy classes}

Selected copper, molybdenum and niobium alloys appear to offer potential as a divertor structure for $\operatorname{ITER}[2,3]$. The specific types of alloys considered include:

- Copper alloys

Solution strengthened: CuBe

Precipitation strengthened: CuCrzr, CuMo

Dispersion strengthened: $\mathrm{Cu}-\mathrm{Al}_{2} \mathrm{O}_{3}$

- Molybdenum alloys

Low alloyed: MozrC, MozrTi

Mo-Re alloys: ( 1 to $47 \%$ ) Re

- Niobium alloys

Low alloyed: NbVZr, $\mathrm{Nb}-1 \mathrm{Zr}$ 
Nominal compositions of these alloys are given in Table 1.

The main advantages of the copper alloys relate to their high thermal. conductivities which tend to reduce the temperature gradient in the wall and the plasma side surface temperature. The main issues for copper alloys relate to their high thermal expansion coefficient and low melting temperature.

The main advantages of the molybdenum alloys are their high melting temperature, which provides greater margin in the event of over-heating caused by loss of flow or tile failure, and relatively low thermal expansion coefficient. The relatively good thermal expansion match with carbon and tungsten armor materials provide advantages associated with lower interfacial stresses. The main issues for the molybdenum alloys relate to their sensitivity to for radiation embrittlement and difficult fabrication/welding.

The niobium alloys exhibit similar advantages as the molybdenum alloys but are more readily weldable and are less susceptible to radiation embrittlement. The main issues relate to hydrogen interactions that could lead to hydrogen embrittlement and excessive tritium inventory or permeation. The thermal stress factor $M$ provides a preliminary basis for comparison of the heat load capability for the candidate alloys. The thermal stress factors celculated from baseline property data for selected alloys are given in Figure $i$ for both the coolant side and plasma side of an idealized 4-mmthick structure with a heat flux of $10 \mathrm{MW} / \mathrm{m}^{2}$ and a coolant side temperature of $150^{\circ} \mathrm{C}$. The figures indicate which types of alloys meet a prescribed set of criteria for $M$ and the ductility $\delta$ at $150^{\circ} \mathrm{C}$ on the coolant side and for the calculated interface temperature. Additional consideration must be given for the effects of radiation and chemical environment on the properties. For the case of ITER, which will operate in a cyclic mode, fatigue is also an important factor. The calculated heat flux limit for an idealized wall of 
selected candidate materials is given in Table 2 for a fatigue life of $10^{4}$ cycles. The calculated heat load limits for the selected copper, molybdenum, and niobium alloys are similar for this case [4]. Copper has high thermal conductivity but also high thermal expansion coefficient. Molybdenum has the lowest thermal expansion coefficient. Niobium has a lower thermal conductivity and higher thermal expansion coefficient than molybdenum; however, a lower elastic modulus and better apparent fatigue properties make up for the conductivity and expansion differences.

The critical new data base for the candidate alloys is reviewed and evaluated below.

\subsection{Copper alloys}

Based on the calculated thermal stress factor and baseline ductility several of the copper alloys appear to meet the preliminary criteria. However, when the effects of interfacial stresses are taken into account for tungsten and carbon armor, the $M$ factors are significantly reduced because of the rather large thermal expansion miss-match

The projected operating temperature range for copper alloys is $50^{\circ}$ to $300^{\circ} \mathrm{C}$, which corresponds to a homologous temperature $\mathrm{T} / \mathrm{Tm}$ of $0.2-0.4$. Since a pronounced effect of neutron irradiation on strength and plasticity of metals is typical for homologous temperatures of $0.3-0.4[5-10]$, neutron irradiation effects are a concern at the higher interface temperatures.

Figures 2 and 3 shows the effects of low fluence neutron irradiation on the yield strength and ductility of candidate copper alloys irradiated at $100^{\circ}$ and $400^{\circ} \mathrm{C}[11,12]$. The yield strengths of the CuBe and CuCrZrMg, alloys are significantly decreased by irradiation at $400^{\circ} \mathrm{C}$. The dispersion strengthened alloy MAGT-0.2 is only moderately affected by irradiation at both 
temperatures. More detailed information on effects of irradiation on copper alloys including swelling, creep and corrosion under irradiation are given in Refs. 13 and 14. The best materials of this group for the divertor applications appear to be the MAGT and GLIDCOP alloys and possibly the CuBe alloys. Softening under irradiation at $300^{\circ}-400^{\circ} \mathrm{C}$ temperature range is a serious concern.

Corrosion/erosion of copper alloys by high velocity water is also a concern. Modest corrosion of GLIDCOP A1-15 (40 $\mu \mathrm{m}$ after $\sim 600 \mathrm{~h}$ ) was observed at $12 \mathrm{~m} / \mathrm{s}$ low pressure water [15]. Severe corrosion of OFHC copper was observed ( $1 \mathrm{~mm}$ after $140 \mathrm{~h}$ ) at $33 \mathrm{~m} / \mathrm{s}$ water under high heat flux conditions $\left(40-60 \mathrm{MW} / \mathrm{m}^{2}\right)[16]$.

\subsection{Molybdenum alloys}

Based on the calculated thermal stress factors and baseline ductility several of the molybdenum alloys appear to meet the preliminary criteria. Because of the better thermal expansion match of molybdenum with tungsten and carbon, the interfacial stresses are much lower than those for the copper alloys. For the reference heat fluxes of $10 \mathrm{MW} / \mathrm{m}^{2}$, the maximum molybdenum alloy temperatures are less than $500^{\circ} \mathrm{C}$, which corresponds to homologous temperatures of 0.1-0.3. The major concern at these low temperatures is low ductility and fracture toughness. Since the Mo--Re alloys were believed to be less sensitive to embrittlement $[2,13]$, they have been suggested as leading candidates. Figure 4 shows a reduction in the DBTT at higher Re concentrations in the Mo-fie alloys while little change is observed in the yield strength [13]. The therma conductivity, thermal expansion coefficient and heat capacity of MoRe alloys as a function of rhenium content are given in Figure 5 [13]. The thermal conductivity decreases rapidly with an increase in 
Re while the thermal expansion shows a modest increase. In order to minimize these changes and still benefit from the decrease in DBTT, a composition of 3 $5 \%$ Re appears optimal.

The effects of low fluence $\left(1\right.$ to $5 \times 10^{21} \mathrm{~cm}^{-2}$ ) irradiation at $\sim 100^{\circ} \mathrm{C}$ in SM-2 and WWR reactors on the yield strength and ductility of selected molybdenum alloys are presented as a function of test temperature in Figures 6 and 7 [17]. Pronounced radiation embrittlement and hardening is observed for all alloys tested. Additional results are presented in reference 17 . Both the Mo and the MozrC exhibit severe loss of ductility when tested below $500^{\circ} \mathrm{C}$. The Mo-5 Re alloy retains significant ductility at $500^{\circ} \mathrm{C}$ but exhibits severe embrittlement at $300^{\circ} \mathrm{C}$ after a fluence of only $10^{21} \mathrm{~cm}^{-2}$. It appears that the DBTT of molybdenum alloys increases by $\sim 500^{\circ} \mathrm{C}$ after fluences of $10^{21}$ $\mathrm{cm}^{-2}$ which corresponds lifetimes of only 2-3 weeks of equivalent operation of the ITER first wall. Therefore, radiation-induced embrittlement remains a feasibility issue for the molybdenum alloys.

\subsection{Niobium alloys}

Recently, low-alloyed niobium alloys were proposed as a candidate divertor structure for ITER $[2,4]$. Although data are limited, selected niobium alloys appear to be much less prone to irradiation embrittlement than the molybdenum alloys [18-21]. For example, the total elongation of $\mathrm{Nb}-1 \mathrm{Zr}$. is $\sim 10 \%$ after irradiation at 25 and $400^{\circ} \mathrm{C}$ to fluences of nearly $4 \mathrm{x}$ $10^{22} \mathrm{~cm}^{-2}$. Although the most ertensive data base exists for $\mathrm{Nb}-12 \mathrm{r}$, a $\mathrm{Nb}-5 \mathrm{~V}-$ $1.252 \mathrm{r}$ alloy (similar to $\mathrm{Cb} 753$ ) exhibits superior base properties. For example the yield and ultimate strengths of $\mathrm{Cb} 753$ at $600^{\circ} \mathrm{C}$ are 640 and $\mathrm{MPa}$, respectively, compared to corresponding values of 210 and $140 \mathrm{MPa}$ for $\mathrm{Nb}-$ $\operatorname{lar}[22]$. The main issues for $\mathrm{Nb}$ alloys relate to hydrogen interactions from 
plasma or from water corrosion. Figure 8 indicates that stable oxide films are formed on a $\mathrm{Nb}-2.5 \mathrm{~V}$ alloy exposed to $300^{\circ} \mathrm{C}$ water and that the corrosion rate is similar to that of zircaloy [23]. Results shown in Table 3 indicate that the hydrogen pickup and tendency for embrittlement strongly valies with alloy composition. Additional data on niobium alloys are given in references 23 and 24 . Based on this information, the comparison of properties with $\mathrm{Nb}-1 \mathrm{Zr}$, and the calculated heat flux limits for $\mathrm{Nb}-1 \mathrm{Zr}$, the $\mathrm{Nb}-5 \mathrm{~V}-1.25 \mathrm{Zr}$ alloy or a similar type of alloy appears to be a good candidate for the divertor structure. Additional data on hydrogen interactions, aqueous corrosion, and radiation embrittlement are required.

\subsection{Summary of divertor structure issues \\ The critical factors for the divertor structure in addition to the heat fiux limits are summarized as follows.}

\subsection{Fabrication/joining}

Selected copper and niobium alloys have a significant advantage with respect to welding/joining. Niobium is readily weldable in an inert atmosphere. Molybdenum is very difficult to weld. The dispersion strengthened copper alloys cannot be welded without substantial loss of mechanical properties.

\subsection{Radiation damage resistance \\ Molybdenum alloys are generally sensitive to low temperature radiation embrittlement. Molybdenum alloys with rhenium were thought to be less sensitive; however, as discussed, Mo-Re alloys also appear to be sensitive to low fluence irradiation and rhenium creates additional safety issues as}


discussed below. If larger amounts of rhenlum are necessary, the thermal conductivity is substantially reduced and cost is significantly inoreased. Niobium and copper appear to offer signiflcant advantages with respect to embrittlement at higher fluence Irradiation conditions.

\subsection{Safety related issues}

The higher melting temperatures of refractory metals provide significant advantages compared to copper in the event of a LOCA. Since rhenium presents significant safety concerns associated with volatile activation products, niobium provides safety advantages compared to the Mo-Re alloys. Also, nlobium and copper provide advantages with respect to lower short term afterheat compared to molybdenum.

\subsection{Thermal expansion match with plasma facing materials}

Both molybdenum and niobium have relatively low thermal expansion coefficients that provide a better match and lower interfacial stresses with carbon and tungsten plasma facing materials. The low modulus of elasticity characteristic of niobium is an advantage for minimizing interfacial stresses. Copper has a better thermal expansion match with beryllium; both being relatively high.

\subsection{Low activation/afterheat considerations}

All of the three materials produce long-lived activation products and are similar with respect to waste management considerations. Therefore, this criterion does not provide a distinguishing characteristic. Niobium and copper exhibit lower short-term afterheat compared to molybdenum. 


\subsection{Aqueous corrosion}

All three materials appear to be compatible with water cooling at the projected temperatures. Minor alloying additions to niobium and molybdenum provide significant benefits for corrosion resistance. Since copper is more susceptible to erosion in high velocity water, the refractory metals have some advantage with respect to erosion in high-velocity water.

\subsection{Hydrogen interactions}

Hydrogen perneabilities in molybdenum and copper are much lower than in niobium. However, appropriate alloying of niobium provides effective oxide barriers when exposed to water. The hydrogen-related issues are critical to the use of niobium alloys. Existing data indicate that selected alloys behave much differently than pure nlobium with respect to hydrogen interactions.

\subsection{Electromagnetic interactions}

Because of the high electrical conductivity of copper, additional design constraints for accommodating disruption loads are required compared to the refractory metals.

\section{References}

[1] International Atomic Energy Agency, IAEA/ITER/DS/18, IAEA, Vienna (1991).

[2] T. Kuroda et al., IAEA/ITER/DS/30, IAEA, Vienna (1991).

[3] D. Smith et al., IAEA/ITER/DS/29 part B, IAEA, Vienna (1991).

[4] D. Smith et al., U.S. Contribution on Plasma Facing Components, ITER-TNPC-1-0-U1-2, Garching, Germany, July 1990.

[5] M.A. Kirk, I.M. Robertson, I.S. Vertano, M.L. Jenkins, and L.L. Funk, Radiation Induced Changes in Microstructure, F.A. Garner, N.M. Packan, A.S. Kumar, Eds., ASTM, Philadelphia, 1986, pp 48-69.

[6] K. Fukumoto, C. Kinoshita, H. Abe, K. Shinohara, ard M. Kutsunada, J. Nucl. Mater., 935-938 (1991).

[7] H. Fukishima, Y. Shimomura, and H. Yoshida, J. Nucl. Mater., 939-942 (1991). 
[8] I. Ishida, S. Susaki, T. Yoshiie, A. Iwase, I. Iwata, and H. Kiritani, J. Nucl. Mater., 913-916 (1991).

[9] H.L. Heinisch, J. Nucl. Mater., 155-157 (1988).

[10] H.M. Erost and J.C. Kennedy, J. Nucl. Mater., 169-173 (1986).

[11] S.A. Fabritsiev, V.V. Rybin, V.R. Rarabash, V.A. Kasakov, and A.S. Pokrovsky, Proc. ICERM-5, Clearwater, FL., November 1991.

[12] I.V. Gorynin, S.A. Fabritsiev, V.V. Rybin, V.A. Kasakov, A.S. Pokrovsky, V.R. Barabash, and Y.G. Prokofiyev, Proc. ICFRM-5, Clearwater, FL., November 1991.

[13] G.M. Kalinin, J. Nucl. Mater., 1193-1198 (1991).

[14] S.A. Fabritsiev, V.A. Gosudarenkova, V.A. Potapova, V.V. Rybin, L.S. Kosachev, V.P. Chakin, A.S. Pokrovsky, and V.R. Barabash, Proc. ICFRM-5, Clearwater, FL., 1991.

[15] R. L. Dobson, J. B. Whitley, "Erosion Corrosion of Copper in a High Velocity Water Environment, Sandia National Laboratories, SAND87-0312, Aug. , 1987.

[16] S. R. Blewer, J. B. Whitley, "Performance and Failure of Generic Beam Dump Panels," Proc. 10th Symposium on Eusion Engineering, IEEE, Philadelphia, PA, pp 1027, 1983.

[17] I.V. Gorynin, V.A. Ignatov, V.V. Rybin, S.A. Fabritsiev, V.A. Kazakov, V.P. Chakin, V.A. Tsykanov, V.A. Barabash, and Y.G. Prokotyev, Proc. ICERM-5, Clearwater, FL., November 1991.

[18] E.W. Wiffen, The T'ensile Properties of East Reactor Neutron Irradiated B.C.C. Metals and Alloys, Defects and Defect Clusters in B.C.C. Metals and Their Alloys, Nuclear Metallurgy, Volume 18, The Metallurgical Society - AIME, 1973, pp 176-197.

[19] R.R.V. Evans, A.G. Weinberg, and R.J. Van Thyne, Irradiation Hardening in Columbium, Acta. Met., 11, February 1963, pp 143-150.

[20] M.J. Makin and E.J. Minter, The Mechanical Properties of Irradiated Niobium, Acta. Met., I, June 1959, pp 361-366.

[21] T.T. Claudson and H.J. Pessl, Irradiation Effects on High Temperature Reactor Structural Materials, BNWL-23, Battelle Pacific Northwest Laboratory, February 1965.

[22] L.J. Pionke and J.W. Davis, Technical Assessment of Niobium Alloys Data Base for Fusion Reactor Applications, U.S. DOE RPT COO-4247-2 (August 1979).

[23] A.B. Hull, I. Purdy, and B.A. Loomis, Proc. ICERM-5, Clearwater, FL, November 1991.

[24] D.T. Peterson, A.B. Hul1, and B.A. Loomis, Hydrogen Embrittlement Considerations in Niobium-Base Alloys for Application in the ITER Divertor, Proc. ICSRM-5, Clearwater, EL., November 1991. 


\section{Table Headings}

1. Nominal Compositions of Candidate Alloys.

2. Calculated Surface Heat Elux Limits for Divertor Structure.

3. Hydrogen Concentrations and Brittleness Index in Corrosion Tested Niobium Alloys Exposed for 30 Days to $300^{\circ} \mathrm{C}$ Water. 
Table 1. Nominal Compositions of Candidate Alloys (w/o)

\section{Copper Alloys}

$\begin{array}{ll}\text { CuBe } & \mathrm{Cu}-2 \mathrm{Be}-0.4 \mathrm{Ni} \\ \text { CuCrZr } & \mathrm{Cu}-0.5 \mathrm{Cr}-0.1 \mathrm{Zr} \\ \text { CuCrZrMg } & \mathrm{Cu}-0.5 \mathrm{Cr}-0.2 \mathrm{Zr}-0.06 \mathrm{Mg} \\ \text { CuMo } & \mathrm{Cu}-5 \mathrm{MO}-0.1 \mathrm{Y} \\ \text { MAGT-0.2 } & \mathrm{Cu}-0.3 \mathrm{Al}-0.1 \mathrm{Hf}-0.08 \mathrm{Ti}-0.3 \mathrm{Al}_{2} \mathrm{O}_{3} \\ \text { MAGT-0.05 } & \mathrm{Cu}-0.1 \mathrm{Al}-0.1 \mathrm{Al}_{2} \mathrm{O}_{3} \\ \text { GLIDCOP-AL15 } & \mathrm{Cu}-0.15 \mathrm{Al}_{2} \mathrm{O}_{3}\end{array}$

Molybdenum Alloys

$\begin{array}{ll}\text { Mo-1Re } & \text { Mo-1Re } \\ \text { Mo-5Re } & \text { Mo-5Re } \\ \text { Mo-9Re } & \text { Mo-9Re }\end{array}$

Ni.obium Alloys

$\begin{array}{ll}\text { NbZr } & \mathrm{Nb}-12 \mathrm{r} \\ \text { NbVZr (Cb753) } & \mathrm{Nb}-5 \mathrm{~V}-1.252 \mathrm{r}\end{array}$


Table 2. Calculated Surface Heat Flux Limits for Divertor Structure

\begin{tabular}{|c|c|}
\hline Material & $\begin{array}{l}\text { Heat Flux Limit* } \\
\text { Expand but not Bend }\end{array}$ \\
\hline $\mathrm{Nb}-12 \mathrm{r}$ & $17-18 \mathrm{MW} / \mathrm{m}^{2}$ \\
\hline $\begin{array}{l}\text { Dispersion } \\
\text { Strengthened } \\
\text { Copper }\end{array}$ & $\sim 14 \mathrm{MW} / \mathrm{m}^{2}$ \\
\hline TZM & $-20 \mathrm{MW} / \mathrm{m}^{2}$ \\
\hline
\end{tabular}
* Nominal $4 \mathrm{~mm}$ wall, $10 \mathrm{MW} / \mathrm{m}^{2}$ surface heat flux, $50^{\circ} \mathrm{C}$ water coolant, $10^{4}$ 
Table 3. Hydrogen Concentrations and Brittleness Index in Corrosion Tested Niobium Alloys Exposed for 30 Days to $300^{\circ} \mathrm{C}$ Water

\begin{tabular}{lccc}
\hline Alloy & $\begin{array}{c}\text { Hydrogen } \\
\text { Concentration, ppm }\end{array}$ & $\begin{array}{c}\text { Percent } \mathrm{H} \\
\text { Captured }\end{array}$ & $\begin{array}{c}\text { Brittleness } \\
\text { Index }\end{array}$ \\
\hline Pure Nb & $730^{\mathrm{a}}$ & 16 & 5 \\
$\mathrm{Nb}-2.5 \mathrm{Zr}$ & 85 & 7 & 1 \\
$\mathrm{Nb}-2.5 \mathrm{~V}$ & 269 & 35 & 5 \\
$\mathrm{Nb}-2.5 \mathrm{Hf}$ & 120 & 8 & 2 \\
$\mathrm{Nb}-2.5 \mathrm{Ta}-2.5 \mathrm{Ti}$ & 63 & 5 & 2 \\
$\mathrm{Nb}-2.5 \mathrm{Mo}$ & 207 & 16 & 5 \\
\hline
\end{tabular}

$a_{\text {Solubility }}$ limit at $25^{\circ} \mathrm{C}-366 \mathrm{ppm}$

$\mathrm{b}_{\mathrm{Brittleness}}$ Index: 5 - Fracture on bending

1 - Neither fracture nor surface cracking of corrosion layer 


\section{Figure Captions}

1. Calculated thermal stress factor versus ductility for candidate structural alloys $=(a)$ copper alloys and ( $b$ ) molybdenum and niobium alloys.

2. Tensile yield strength and elongation at $100^{\circ} \mathrm{C}$ for unirradiated and irradiated copper alloys.

3. Tensile yield strength and elorigation at $400^{\circ} \mathrm{C}$ for unirradiated and irradiated copper alloys.

4. Yield strength and ductility as a function of Re concentration fur binary Mo-Re alloys.

5. Physical properties of Mo-Re alloys as a function of Re concentrations.

6. Yield strength and tensile ductility as a function of test temperature for $\mathrm{Mo}$ and Mo-5Re alloy after irradiation to $10^{21} \mathrm{~cm}^{-2}$ at $100^{\circ} \mathrm{C}$ in $\mathrm{SM}-2$ reactor.

7. Yield strength and tensile ductility as a funct,ion of test temperature for Mo and MozrC after irradiation to $5 \times 10^{21} \mathrm{~cm}^{-2}$ at $90^{\circ} \mathrm{C}$ in WWR reactor.

8. Corrosion of $\mathrm{Nb}, \mathrm{Nb}-2.5 \mathrm{Ta}$ and $\mathrm{Nb}-2.5 \mathrm{~V}$ as a function of time in $300^{\circ} \mathrm{C}$ water. 


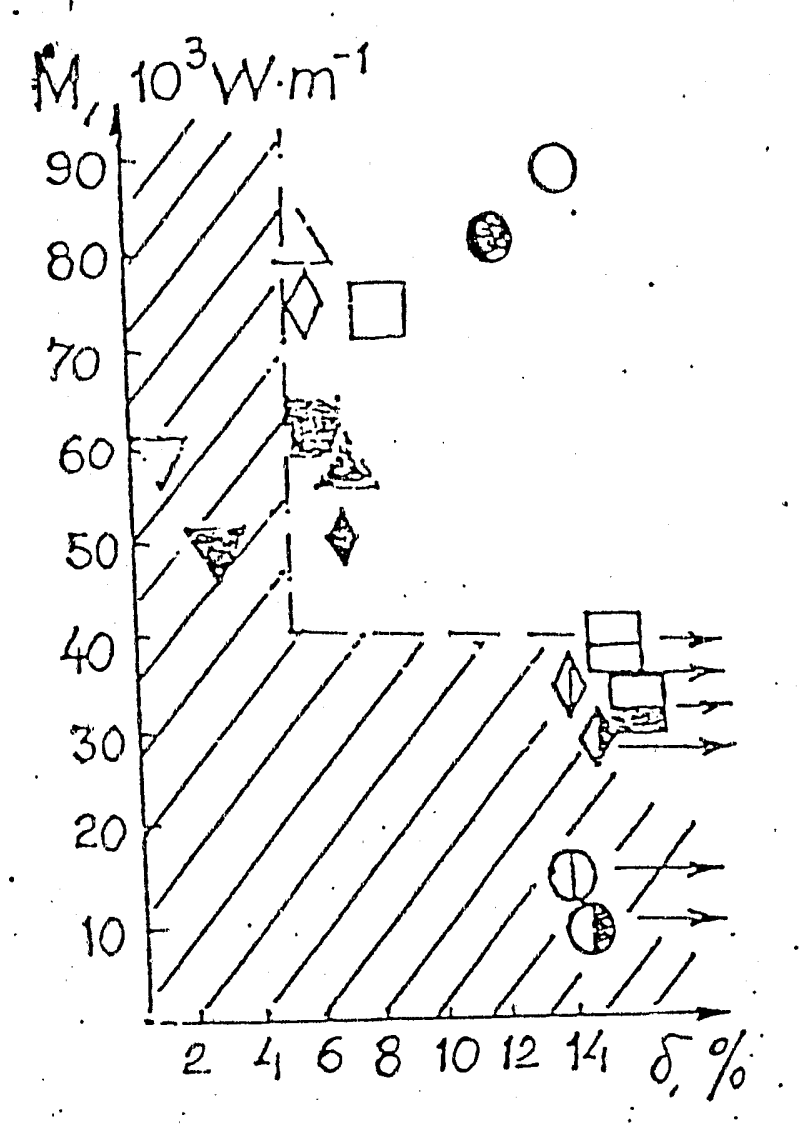

$M, 10^{3} \mathrm{~W} \cdot \mathrm{m}^{-1}$

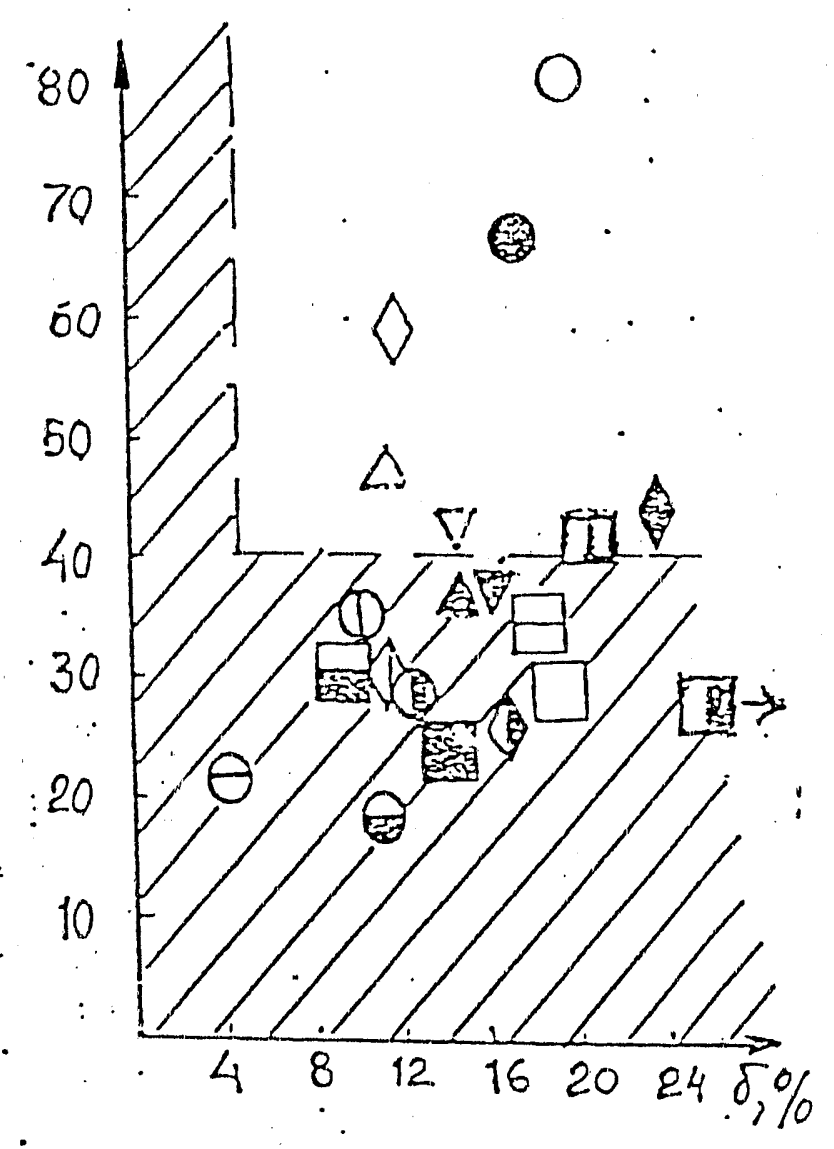

interface

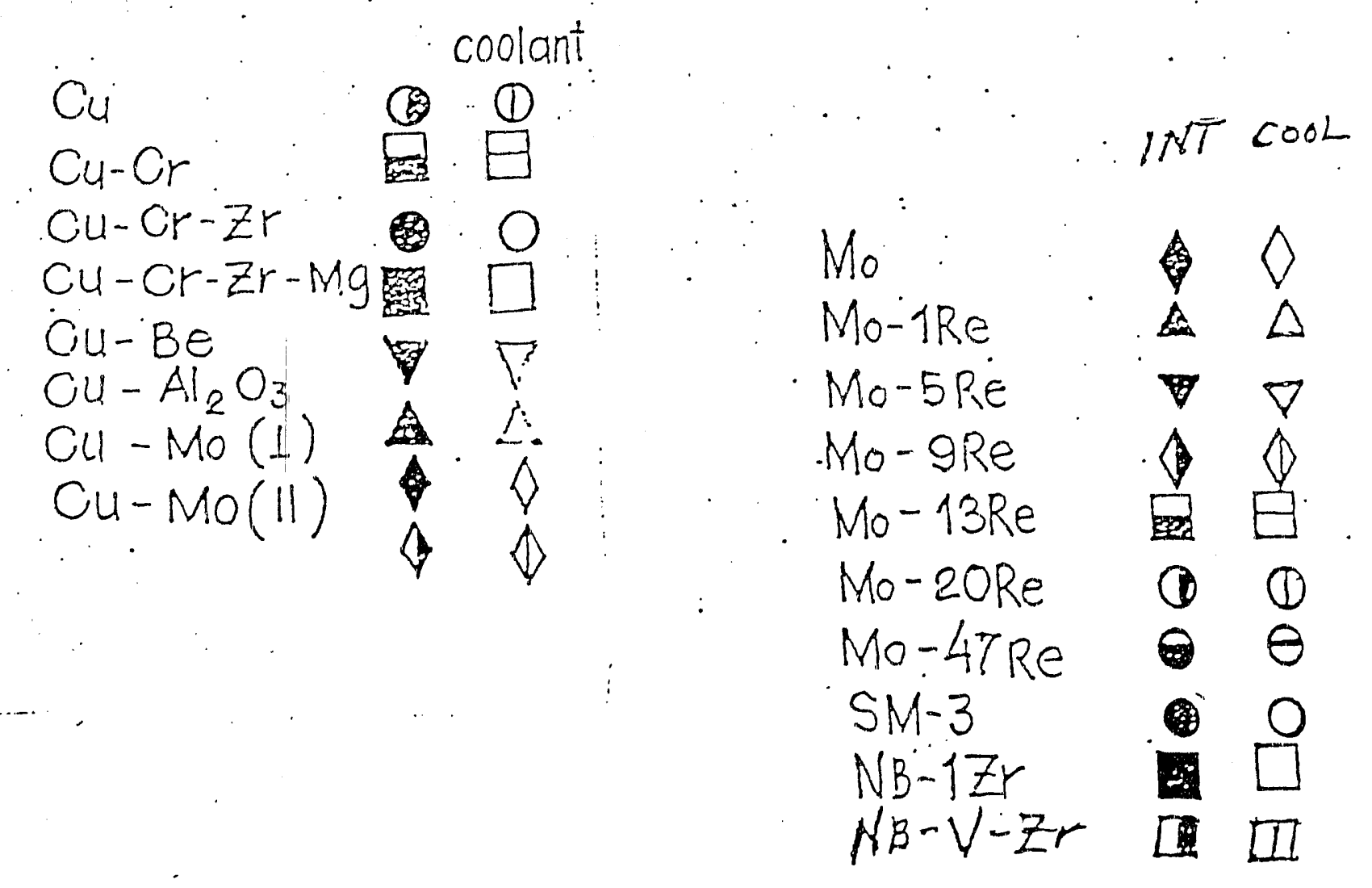



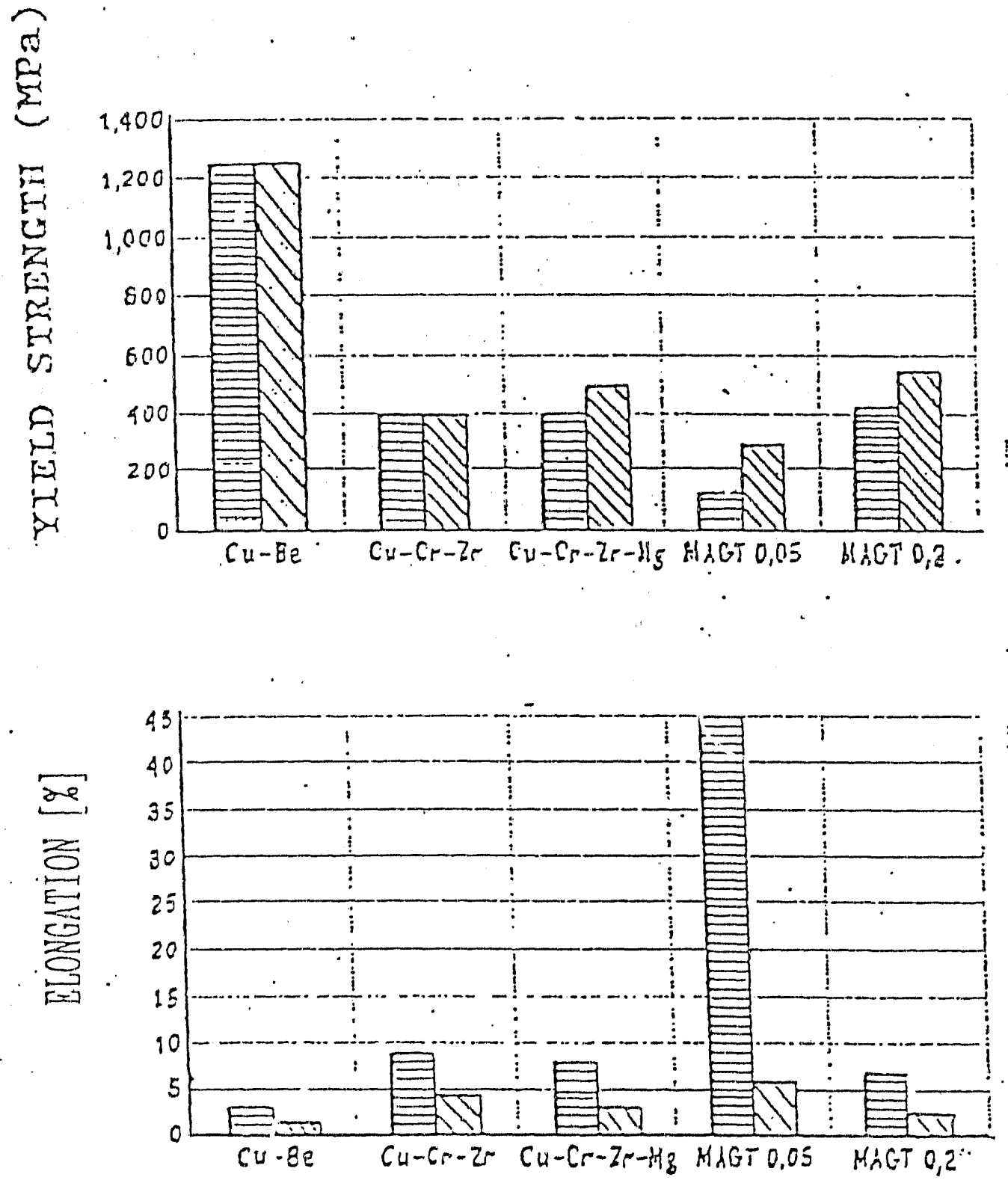

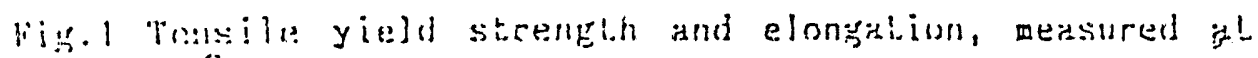

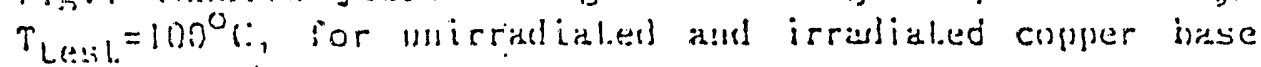
alloys.
国 - mirraliated;
ES

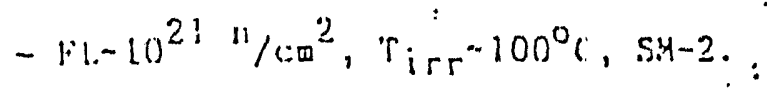



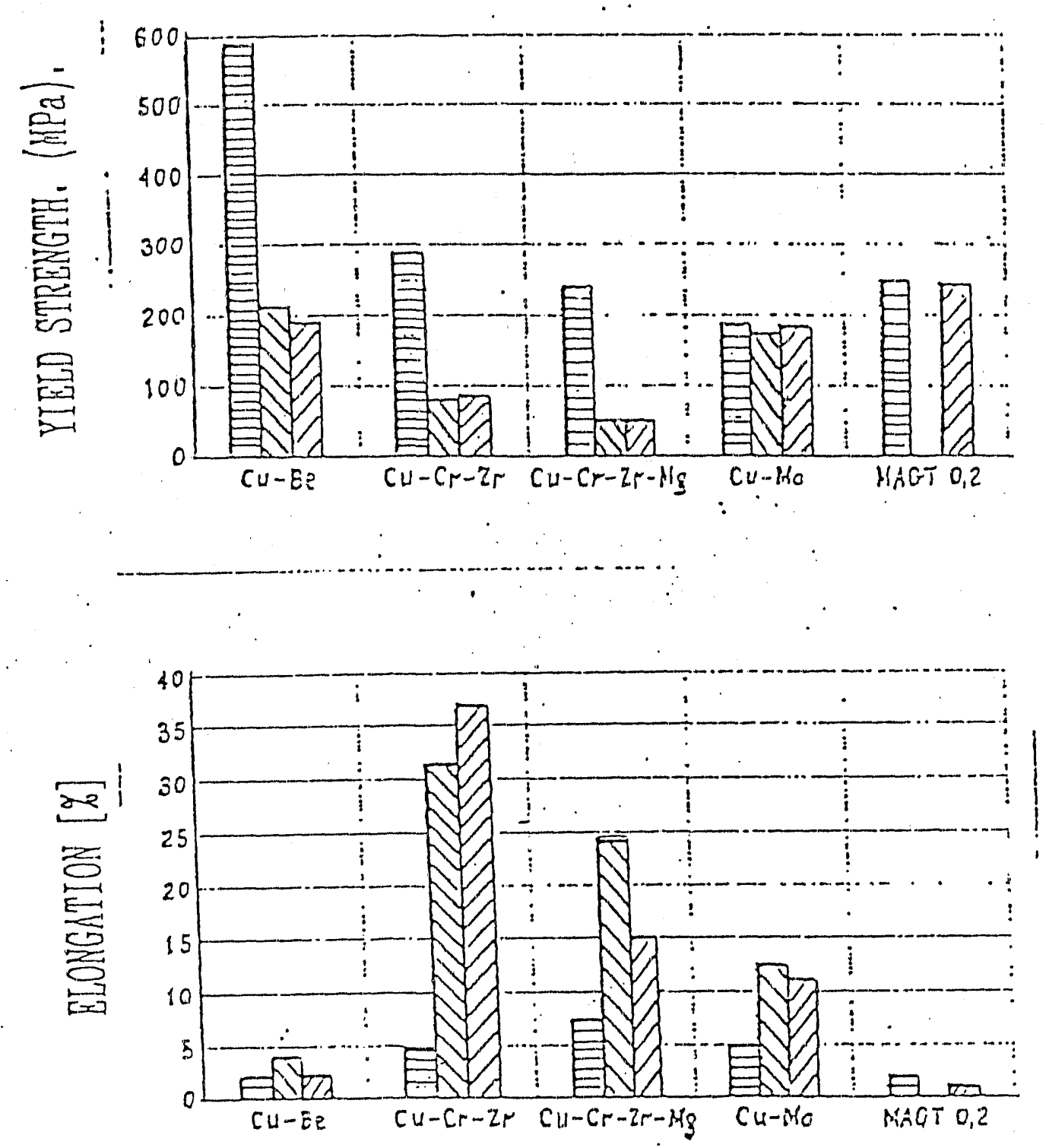

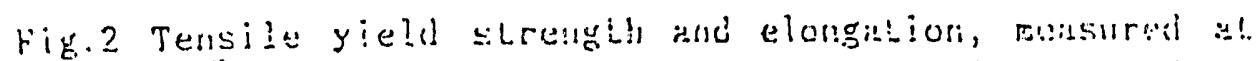

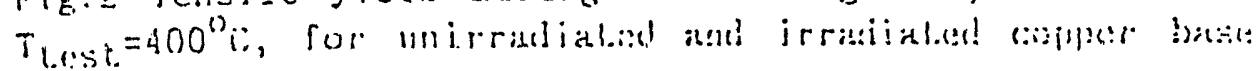
alloys.

E. - nuirra!imlet?

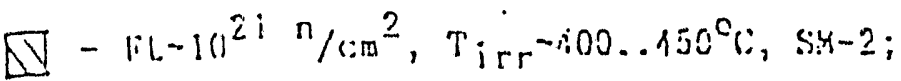

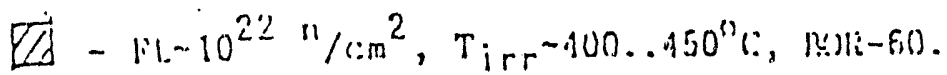

$$
\text { Fig } 3
$$




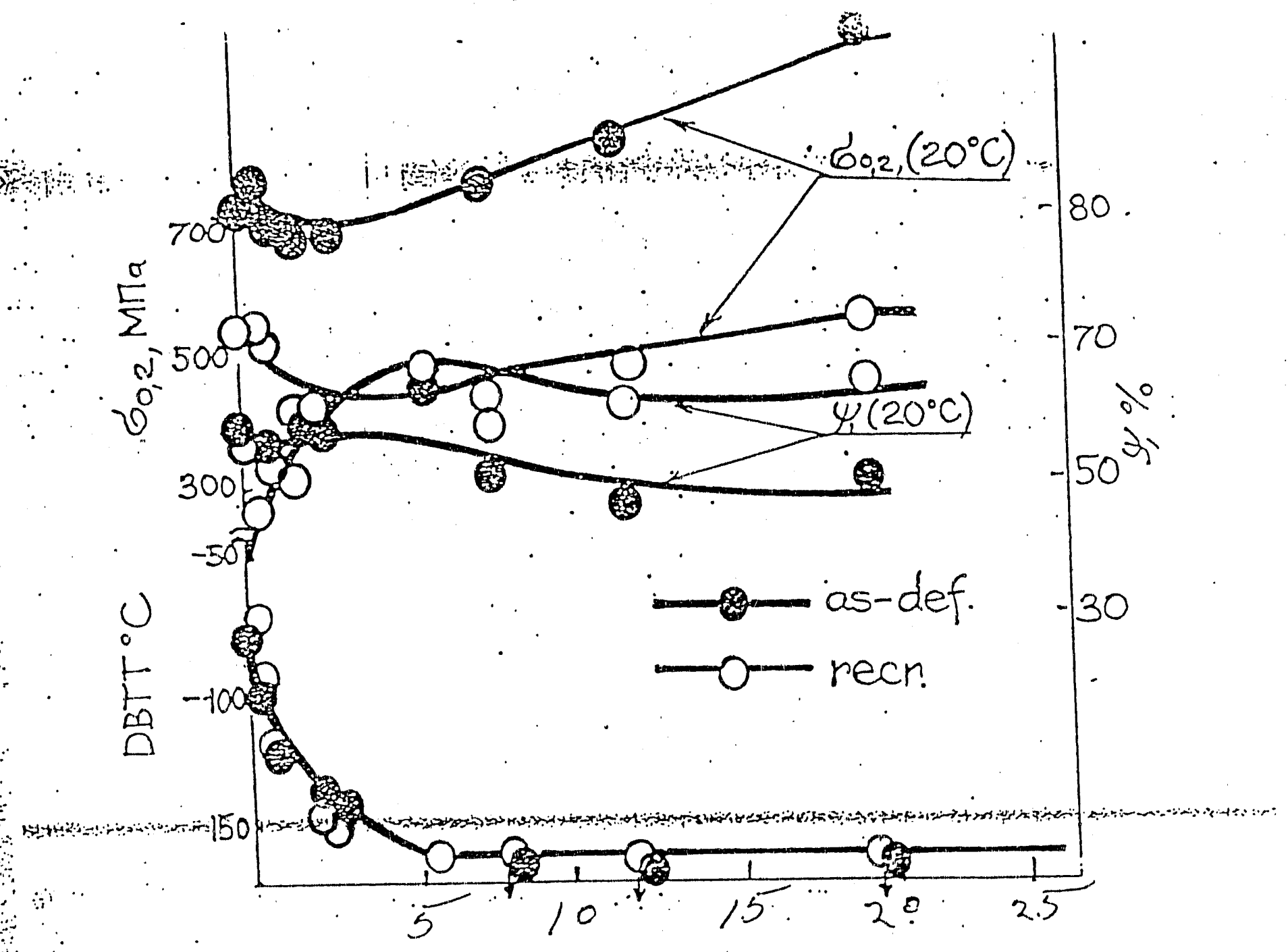

Re, \%

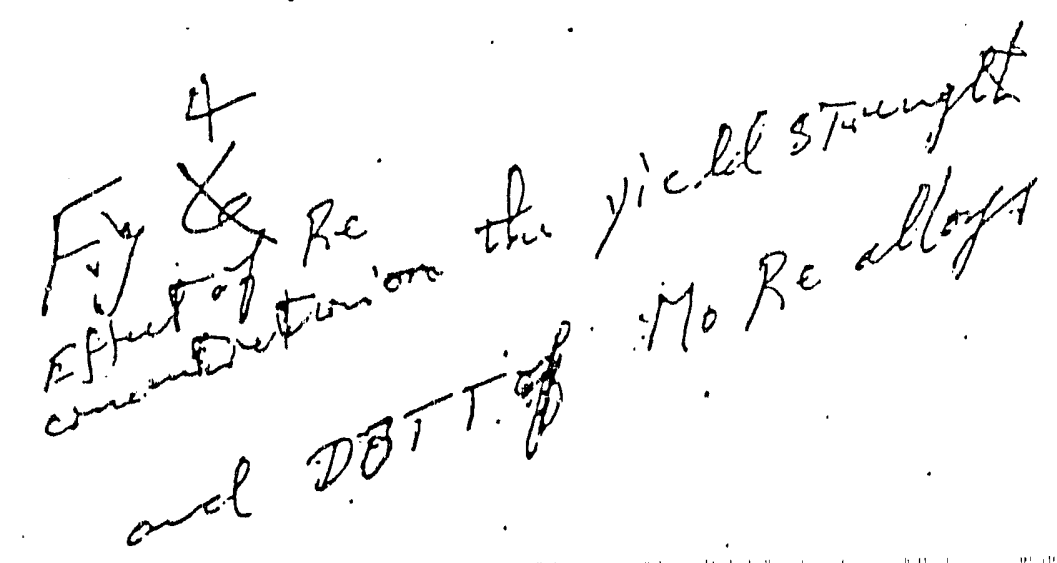




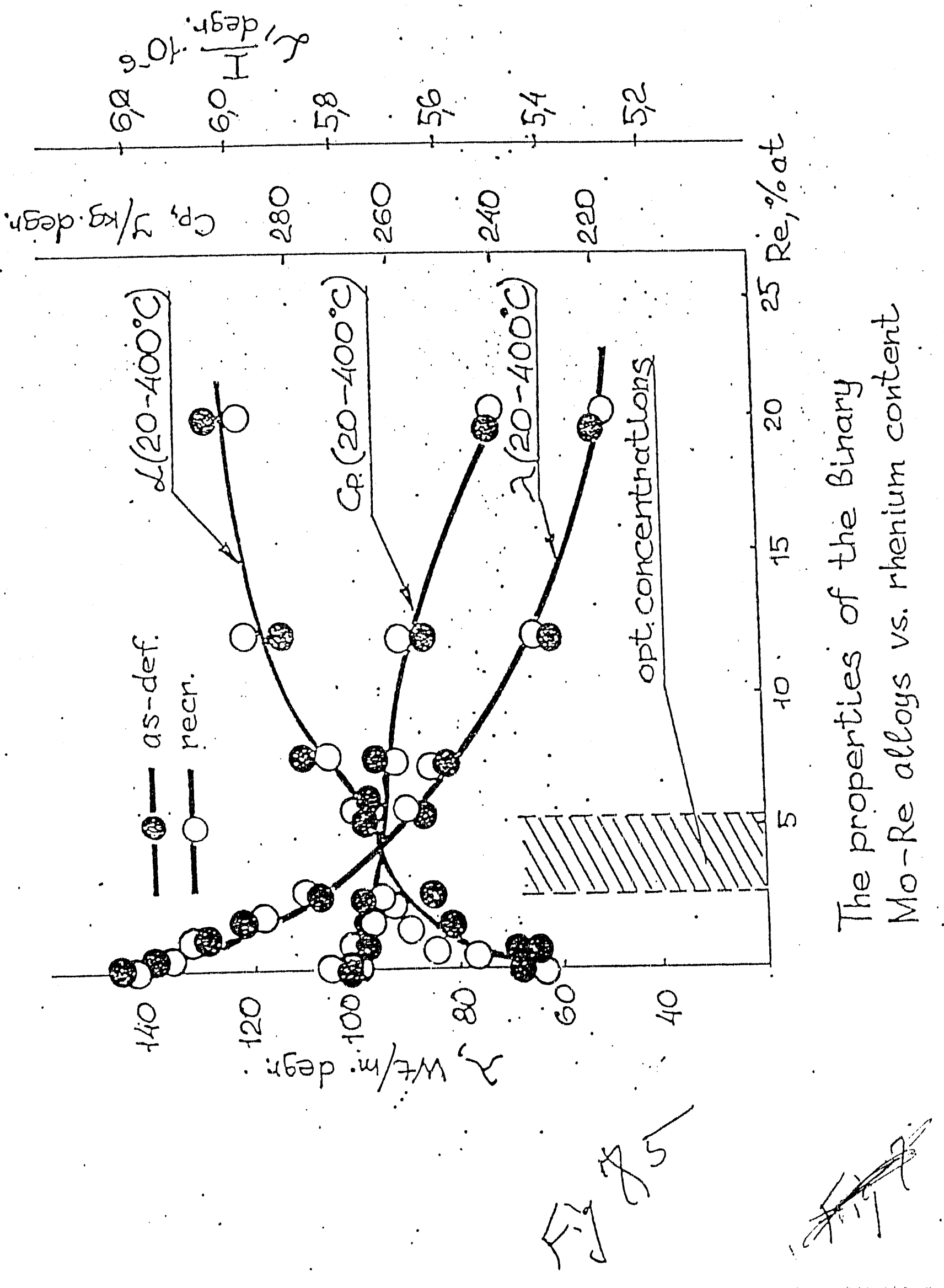



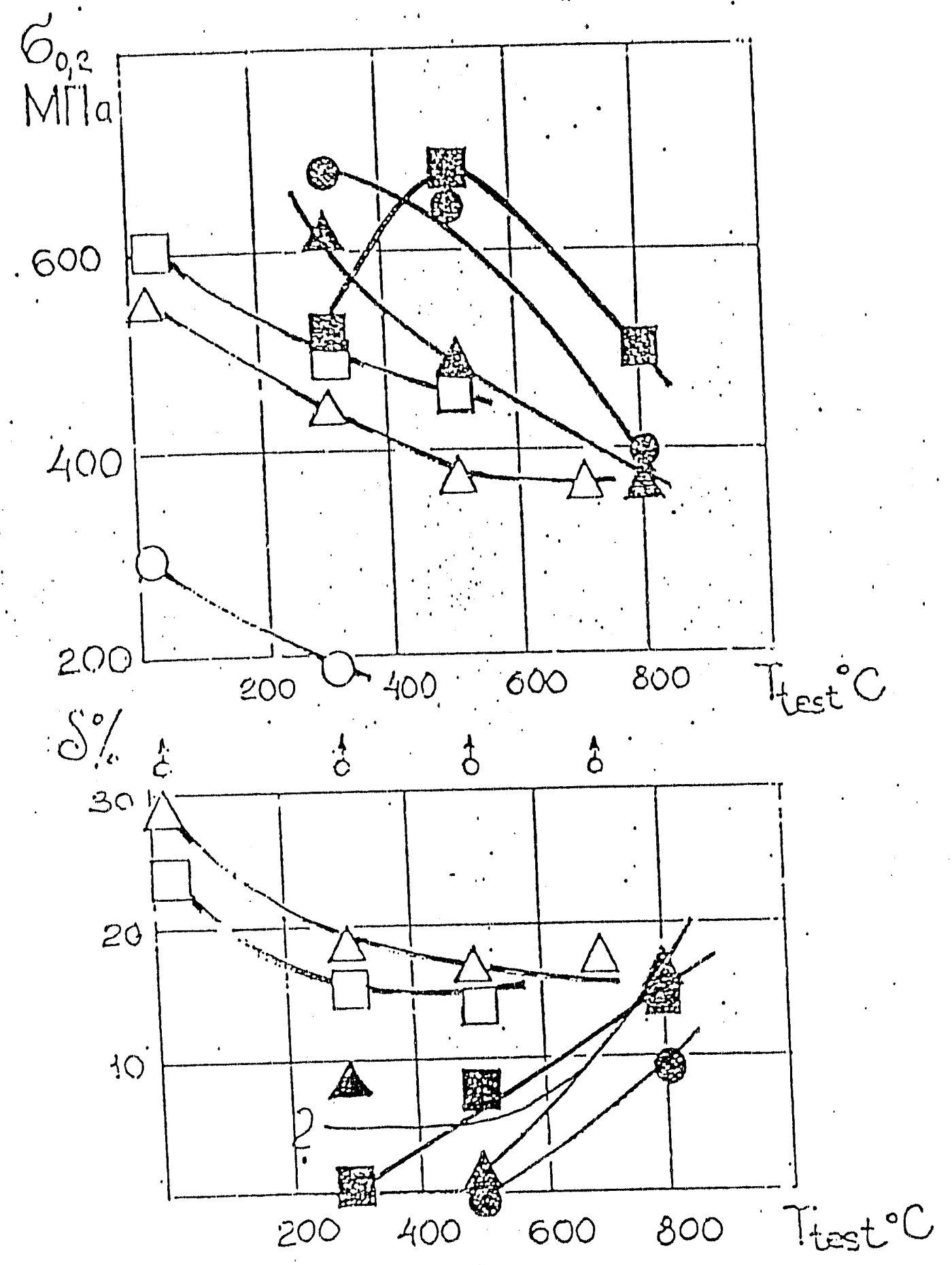

material initial state irrad SM-2

Mo def $\triangle$ Miru

Fig $\$ 6$

Mo recr O

Mo5Re def $\square \quad \phi=10^{25} \mathrm{H} / \mathrm{m}^{2}$ 

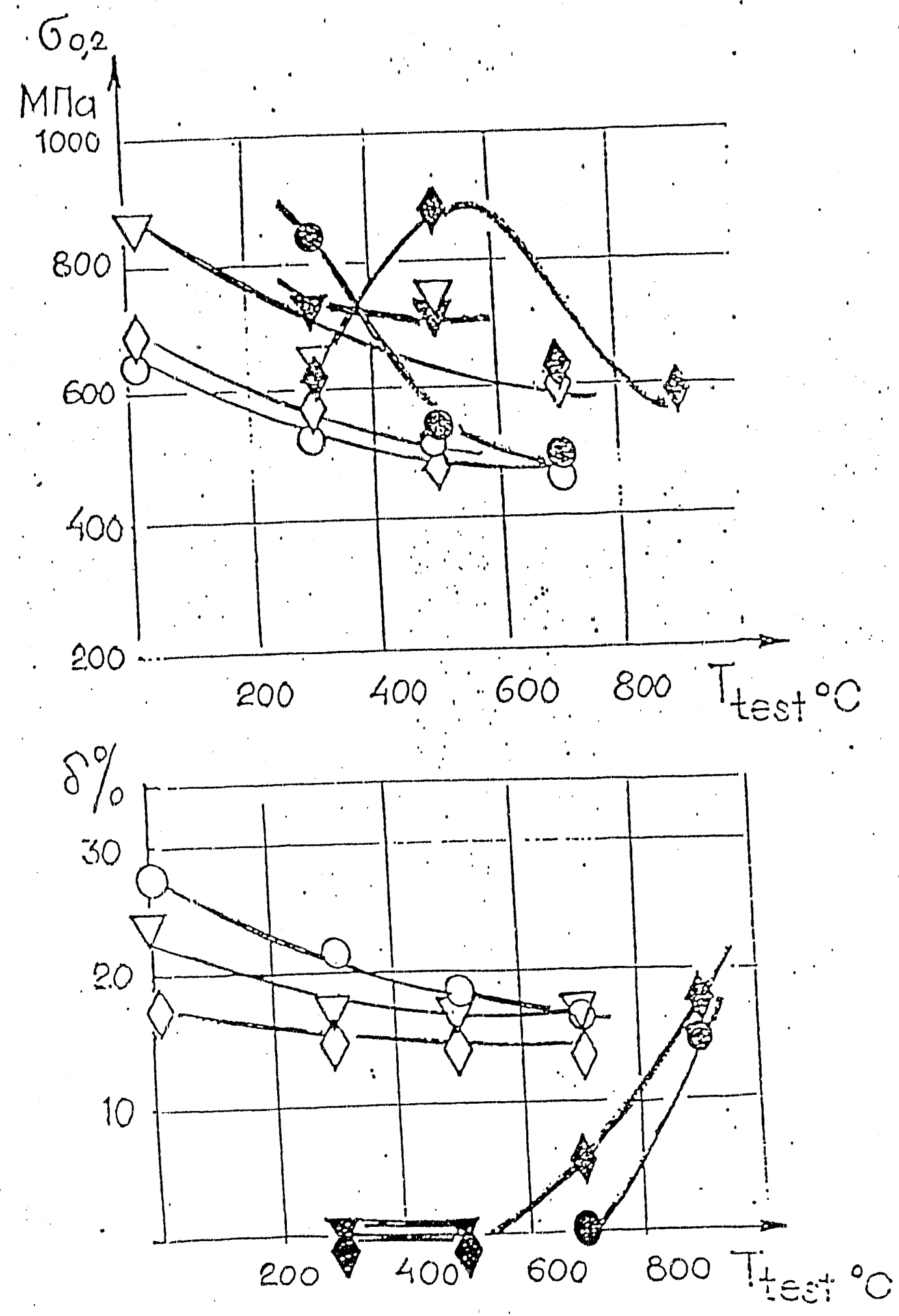

materio! initial srate irrad.WWR. Mozrc def $\nabla$ MozrC recr $O$
Mo ReC ann $\diamond$

$$
\begin{aligned}
& T_{i r r}=90^{\circ} \mathrm{C} \\
& F=5.10^{23} \mathrm{n} / \mathrm{m}
\end{aligned} F^{i g}
$$

9
7 

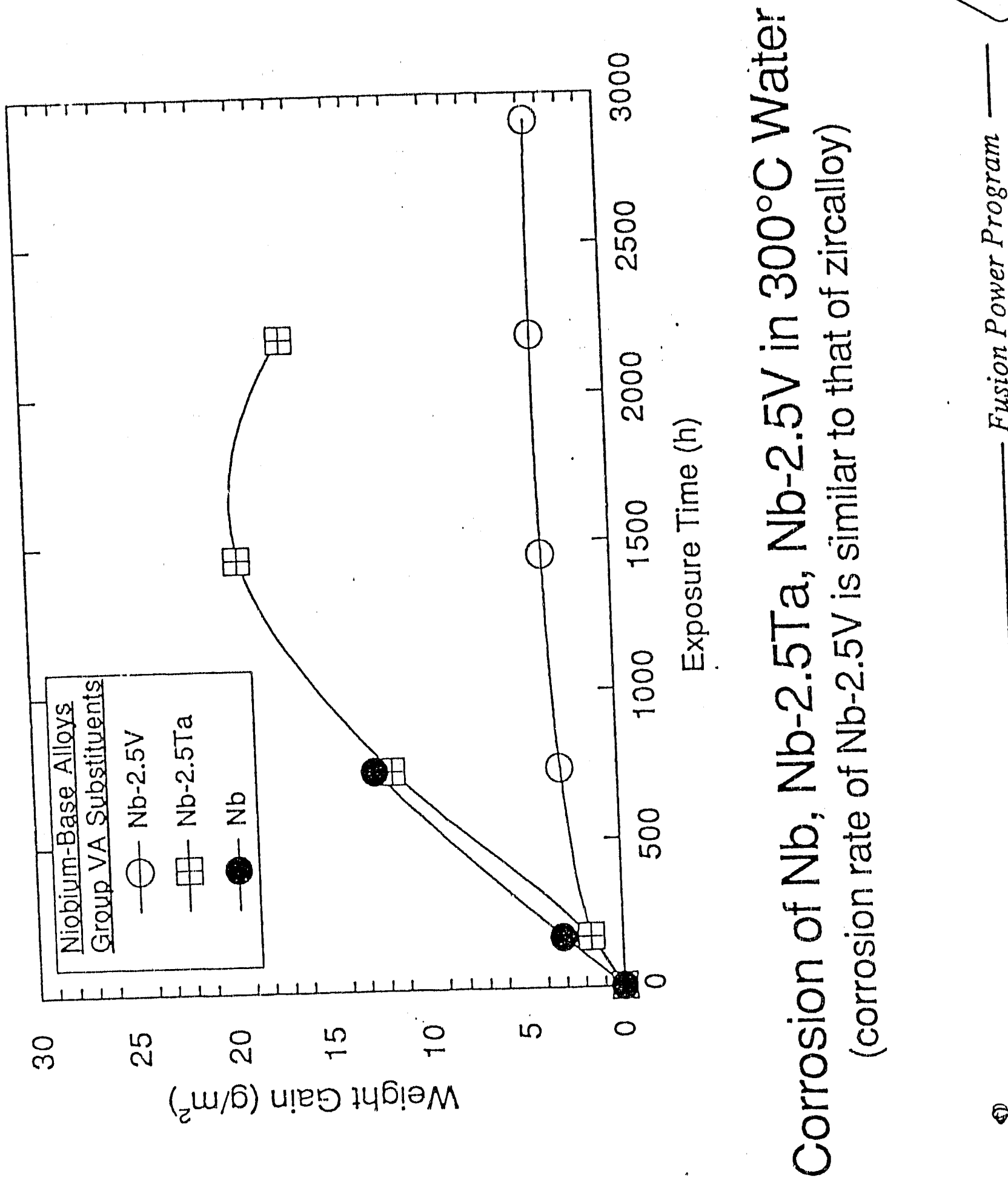

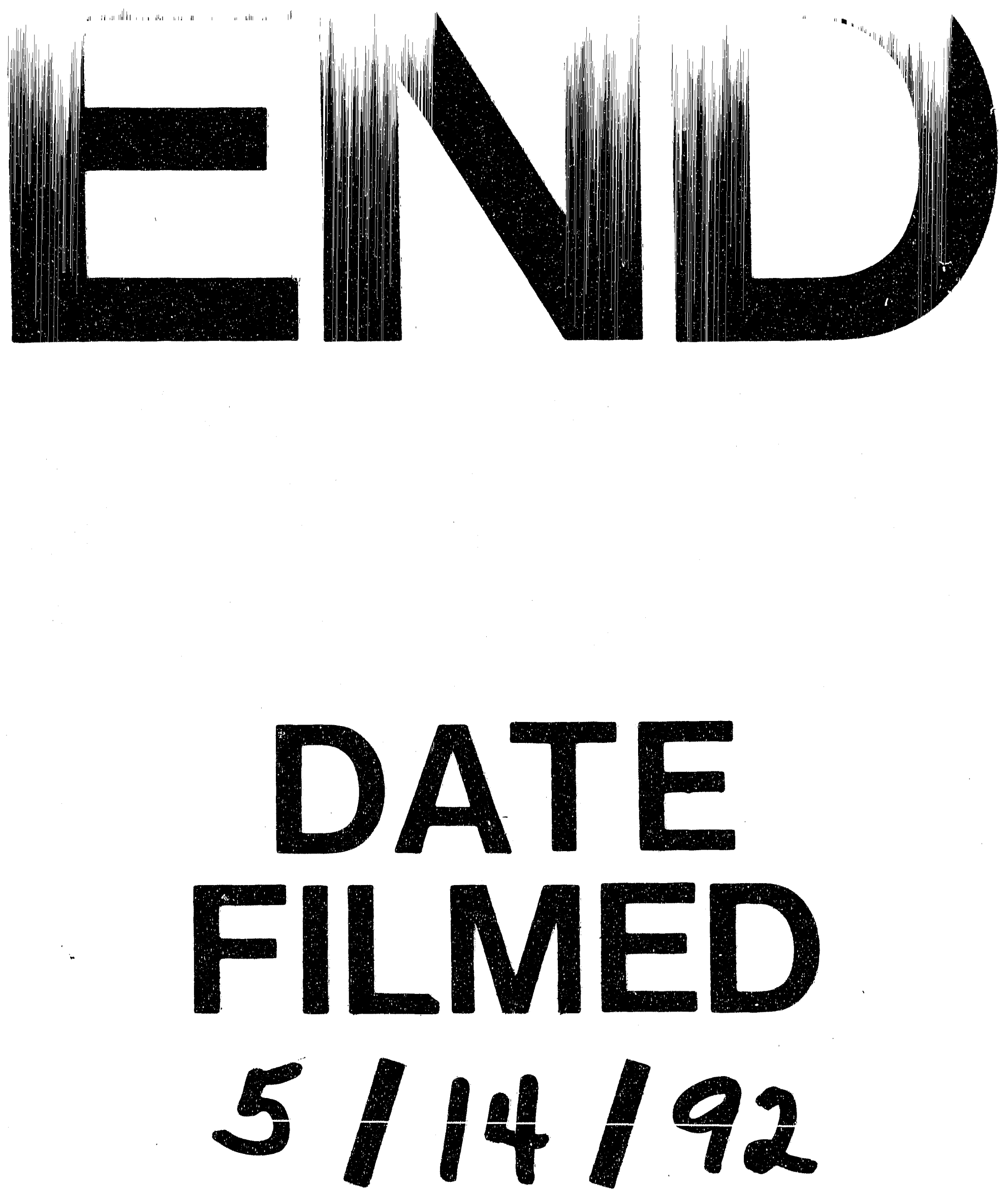

1 
